\title{
The Effectiveness of Cinacalcet as an Adjunctive Therapy for Hereditary 1,25 Dihydroxyvitamin $\mathrm{D}_{3}$-Resistant Rickets
}

\author{
Ayşehan AkıncI ${ }^{1}$, İsmail Dündar ${ }^{1}$, Meltem Kıvıılım² \\ ${ }^{1}$ Inönü University Faculty of Medicine, Department of Pediatric Endocrinology, Malatya, Turkey \\ ${ }^{2}$ Inönü University Faculty of Medicine, Department of Developmental and Behavioral, Malatya, Turkey
}

\begin{abstract}
What is already known on this topic?
Hereditary vitamin D-resistant rickets (HVDRR) is a rare autosomal recessive disease characterized by early-onset severe rickets, alopecia, hypocalcemia, and secondary hyperparathyroidism in the face of an elevated serum 1,25 dihydroxyvitamin $\mathrm{D}_{3}\left[1,25(\mathrm{OH}) 2 \mathrm{D}_{3}\right]$ level. Secondary hyperparathyroidism from inadequate calcium absorption in the gut is the underlying pathophysiology for the rachitic changes in HVDRR. The recent availability of the calcimimetic agent cinacalcet enables the suppression of parathyroid hormone secretion through activation of the calcium-sensing receptors.
\end{abstract}

\section{What this study adds?}

We observed that cinacalcet is effective in the management of secondary hyperparathyroidism and that it improves the biochemical and radiological findings in HVDRR. The calcimimetic agent, cinacalcet, may be considered as an adjunct to high-dose $1,25(\mathrm{OH}) 2 \mathrm{D}_{3}$ (calcitriol) and calcium therapy in the management of children with HVDRR.

\section{Abstract}

High doses of oral calcium or long-term calcium infusions are recommended to correct the hypocalcemia and secondary hyperparathyroidism in patients with hereditary 1,25 dihydroxyvitamin $\mathrm{D}_{3}$-resistant rickets (HVDRR). Preliminary studies revealed that calcimimetics may be a safe and effective therapeutic choice in children with secondary hyperparathyroidism. Our aim was to observe the efficacy of cinacalcet in the normalization of secondary hyperparathyroidism and hypophosphatemia in two siblings aged 2.5 years and 6 months with HVDRR who did not respond to traditional treatment regimes. Both patients were admitted to the hospital with severe hypocalcemia. They were treated with high doses of calcitriol and calcium infusions intravenously. Secondary hyperparathyroidism was normalized temporarily, but did not improve completely. Cinacalcet $(0.25 \mathrm{mg} / \mathrm{kg})$ once a day along with the high doses of oral calcium and calcitriol was added to the treatment schedule. After 3 months, biochemical and radiologic findings reverted to normal. Our findings indicate that cinacalcet is effective in normalizing the hyperparathyroidism and hypophosphatemia in these cases and in improving the bone pathology.

Keywords: Cinacalcet, hereditary vitamin D-resistant rickets, secondary hyperparathyroidism

\section{Introduction}

Hereditary vitamin D-resistant rickets (HVDRR) is a rare autosomal recessive disorder caused by mutations in the vitamin $D$ receptor (VDR) gene. It is characterized by severe rickets, hypocalcemia, hypophosphatemia, secondary hyperparathyroidism (hPTH), increased serum alkaline phosphatase (ALP) and $1 \alpha, 25$ dihydroxyvitamin $\mathrm{D}_{3}\left[1,25(\mathrm{OH})_{2} \mathrm{D}_{3}\right]$ levels $(1,2)$. Total or partial alopecia and dermal cysts are encountered in a subset of these pediatric patients. The VDR gene is expressed in most tissues of the body, including intestines, kidney, bones, and keratinocyte of hair follicles (3). Alopecia due to the defective $V D R$ gene activity within keratinocytes appears in approximately two-thirds of the cases and is considered as a marker of disease severity and response to therapy. There is no standard therapy protocol for patients with HVDRR, and patients with alopecia are usually more resistant to 
treatment and require high doses of $1,25(\mathrm{OH})_{2} \mathrm{D}_{3}$ and also large doses of calcium, either administered orally or intravenously $(4,5,6)$. Most patients with HVDRR require prolonged hospitalization for intravenous calcium therapy in order to maintain normocalcemia. Especially in infants, prolonged hospitalization and high infection risk related to catheter application are a few of the difficulties of this treatment regime. Another risk is unsustained parathyroid hormone (PTH) suppression and related hypophosphatemia and poor healing of the skeletal findings. It is possible to suppress the development of secondary hPTH, normalize serum phosphate levels, and resolve the rachitic changes with cinacalcet, which is a calcimimetic (7). We report the effectiveness of cinacalcet on the normalization of metabolic parameters and radiological healing of rickets in two sisters with HVDRR who had inadequately controlled secondary hPTH despite treatment with oral/or intermittent i.v. calcium infusion and calcitriol in high doses.

\section{Case Reports}

\section{Case 1}

The proband was a 2.5-year-old female child who was admitted to our hospital for evaluation of her seizures, deformities of lower extremities, failure to thrive, and alopecia. She was born to consanguineous parents as a full-term infant by normal spontaneous vaginal delivery, with a birth weight of $3250 \mathrm{~g}$ and a birth length of $50 \mathrm{~cm}$. Her mother had received prenatal care and had taken vitamins regularly. The patient had been almost exclusively breastfed since birth up to 15 months. In addition, she had received 25-hydroxyvitamin $\mathrm{D}_{3}\left[25(\mathrm{OH}) \mathrm{D}_{3}\right] 400$ IU per day for one year. At presentation, her height was $83 \mathrm{~cm}$ (3$10 \%$ p), her weight was $10.7 \mathrm{~kg}$ (weight for height: $25 \%$ p), and head circumstance was $47 \mathrm{~cm}(3-97 \%$ p). She had rachitic rosary over the chest wall, widening of wrists and ankles, and "X" deformity of lower extremities. Her head appeared disproportionately large, but head circumference was within the normal range with an open anterior fontanel and frontal bossing. She was able to sit without support, but her ability to stand and walk were restricted due to the "X" deformity of the legs. She had frontal bossing, near total alopecia, and sparse eyebrows and eyelashes (Figure 1). Laboratory results revealed normal levels for serum electrolytes, serum albumin, blood urea nitrogen (BUN), and creatinine. Other laboratory results were as follows: serum calcium (Ca): $7.5 \mathrm{mg} / \mathrm{dL}$ (8.8-10.8), serum phosphorus (P): $2.3 \mathrm{mg} / \mathrm{dL}$ (4.5-5.5), ALP: $2278 \mathrm{U} / \mathrm{L}$ (80-220), intact PTH: $1194 \mathrm{pg} / \mathrm{mL}$ (10-71 pg/mL), 25(OH) $\mathrm{D}_{3}: 25.2 \mathrm{ng} / \mathrm{mL}$ (10$44 \mathrm{ng} / \mathrm{mL}), 1,25(\mathrm{OH})_{2} \mathrm{D}_{3}: 59 \mathrm{pg} / \mathrm{mL}(16-65 \mathrm{pg} / \mathrm{mL})$. Serum
Ca, P, and ALP were determined by spectrophotometric method (Abbott, Architect C 16.000, IL, USA), intact PTH by chemiluminescent method (Beckman Caulter DxI800), and $25(\mathrm{OH}) \mathrm{D}_{3}$ by electro chemiluminescent method (Roche, Cobas e-411). Serum electrolytes, albumin, BUN, and creatinine levels were within normal ranges. Serum $1,25(\mathrm{OH})_{2} \mathrm{D}_{3}$ level was in the upper limit of the normal range. The skeletal survey showed generalized osteopenia with advanced features of rickets manifested by cupping and fraying at the metaphyseal ends of long bones of upper and lower extremities (Figure 1a). VDR gene sequence analysis was performed by using MiSeq next-generation sequencing (NGS) platform, a Food and Drug Administrationapproved diagnostic system (IIIumina, San Diego, CA, USA), and it was shown as a homozygote stop-codon mutation (c. 148C > T) with mutation number: NM-001017535 (Figure 2). This mutation was described previously (8). Parents were heterozygous for the same mutation.

As shown in Table 1, the patient was initially treated with high doses of oral calcium (elemental Ca: $2 \mathrm{~g} /$ day), phosphate ( $1 \mathrm{~g} /$ day), and calcitriol $\left[1 \alpha-25(\mathrm{OH}) \mathrm{D}_{3}\right]$ ( $2 \mu \mathrm{g} /$ day). Elemental calcium and calcitriol were subsequently increased to 4 g/day and $6 \mu \mathrm{g} /$ day, respectively. After 8 weeks of this protocol, serum Ca concentration became close to normal levels, but PTH was not suppressed and ALP was still high, and no radiological improvement was observed. Treatment was continued with high-dose oral calcium and calcitriol. After 6 weeks, the patient was admitted to hospital again with hypocalcemic seizures. During this period, HVDRR was confirmed by $V D R$ gene mutation and intravenous calcium infusion was initiated. Elemental calcium was administrated at $150 \mathrm{mg} / \mathrm{kg} /$ day, infused via central line over a period of 10 hours for five days in a month. She
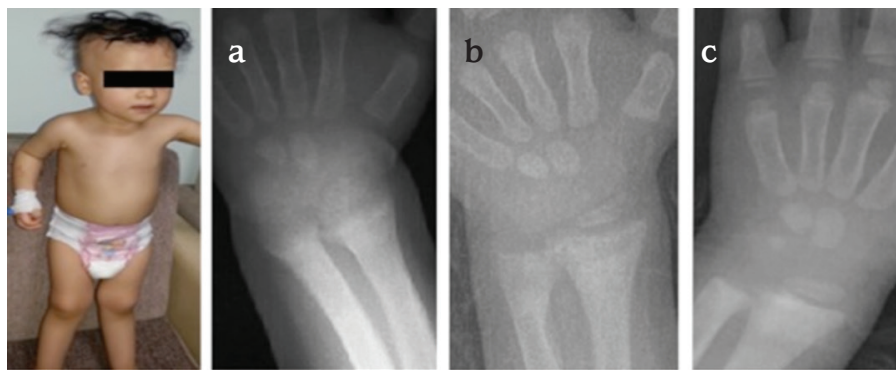

Figure 1. Alopecia and rickets in case 1

1a. Before treatment: Anteroposterior radiography of the patient's hand demonstrating cupping of the metaphyseal region

1b. After treatment with high dosages of i.v. calcium infusion, wrist $\mathrm{x}$-ray showing partial healing of the rickets findings

1c. The x-ray of the wrist showing progressive healing of rickets while the child was receiving high-dose oral calcium, calcitriol, and cinacalcet 
has been on this treatment for 4 months. We observed a decrease in PTH and ALP levels and normalization of serum $\mathrm{P}$ levels only during the periods of intravenous calcium infusion administration. After 4 steps of i.v. calcium infusion, partial healing in skeletal bone rickets findings were observed (Figure 1b); however, when the calcium infusion was stopped, secondary hPTH, increased ALP levels, and hypophosphatemia developed again and rachitic

Table 1. Effects of treatment with elemental calcium (oral/i.v.), calcitriol, and cinacalcet on serum calcium, phosphorus, alkaline phosphatase, and parathyroid hormone levels in case 1

\begin{tabular}{|c|c|c|c|c|c|}
\hline Date & $\begin{array}{l}\mathrm{Ca} \\
(\mathrm{mg} / \mathrm{dL})\end{array}$ & $\begin{array}{l}\mathrm{P} \\
(\mathrm{mg} / \mathrm{dL})\end{array}$ & $\begin{array}{l}\text { ALP } \\
\mathrm{U} / \mathrm{L}\end{array}$ & $\begin{array}{l}\text { PTH } \\
\mathrm{pg} / \mathrm{mL}\end{array}$ & Treatment \\
\hline First admission & 7.2 & 2.3 & 2278 & 1194 & $\begin{array}{l}\text { Elemental Ca oral: } 2 \text { g/day } \\
\text { Calcitriol: } 2 \mu \mathrm{g} / \text { day } \\
\text { P: } 1 \text { g/day }\end{array}$ \\
\hline $\begin{array}{l}4^{\text {th }} \text { week } \\
\text { (second visit) }\end{array}$ & 7.8 & 2.4 & 2127 & 1078 & $\begin{array}{l}\text { Elemental Ca oral: } 4 \text { g/day } \\
\text { Calcitriol: } 4 \mu \mathrm{g} / \text { day } \\
\text { P: } 1.5 \text { g/day }\end{array}$ \\
\hline $\begin{array}{l}8^{\text {th }} \text { week } \\
\text { (third visit) }\end{array}$ & 8.5 & 2.8 & 2047 & 1036 & $\begin{array}{l}\text { Continued with same protocol } \\
\text { no radiological changes }\end{array}$ \\
\hline $\begin{array}{l}\text { After } 6 \text { weeks of } 3^{\text {rd }} \text { visit } \\
\text { First-step i.v. Ca infusion for } 5 \text { days in a month }\end{array}$ & 6.8 & 1.8 & 1427 & 940 & $\begin{array}{l}\text { Elemental Ca i.v.: } 150 \mu \mathrm{g} / \mathrm{kg} / \text { day } \\
\text { P: } 2 \text { g/day } \\
\text { Calcitriol: } 6 \mu \mathrm{g} / \text { day }\end{array}$ \\
\hline After first step of i.v. Ca therapy for 5 days & 9.4 & 2.7 & 1540 & 95 & $\begin{array}{l}\text { Elemental Ca oral: } 4 \text { g/day } \\
\text { Calcitriol: } 6 \mu \text { g/day } \\
\text { P: } 2 \text { g/day }\end{array}$ \\
\hline After 4 weeks of i.v. Ca infusion therapy & 7.9 & 3 & 1887 & 887 & $\begin{array}{l}\text { Elemental Ca oral: } 4 \text { g/day } \\
\text { Calcitriol: } 6 \mu \text { g/day } \\
\text { P: } 2 \text { g/day }\end{array}$ \\
\hline $\begin{array}{l}\text { After oral drugs for } 2 \text { months, second-step i.v. } \\
\text { Ca therapy applied }\end{array}$ & 7.2 & 1.5 & 1651 & 1085 & $\begin{array}{l}\text { Elemental Ca i.v.: } 150 \mu g / \mathrm{kg} / \text { day } \\
\text { Calcitriol: } 6 \mu g / \text { day } \\
\text { P: } 2 \text { g/day }\end{array}$ \\
\hline After 5 days of i.v. elemental Ca infusion & 9.4 & 2.1 & 1433 & 90 & $\begin{array}{l}\text { Elemental Ca oral: } 4 \text { g/day } \\
\text { Calcitriol: } 6 \mu \mathrm{g} / \text { day } \\
\text { P: } 2 \text { g/day }\end{array}$ \\
\hline After 4 weeks of i.v. Ca infusion off & 7.1 & 2.4 & 1638 & 681 & $\begin{array}{l}\text { Elemental Ca i.v.: } 150 \mathrm{mg} / \mathrm{kg} / \text { day } \\
\text { Calcitriol: } 6 \mu \mathrm{g} / \text { day }\end{array}$ \\
\hline After 4 steps of i.v. Ca infusion & 7.5 & 2.6 & 1480 & 716 & $\begin{array}{l}\text { P: } 2 \text { g/day } \\
\text { Partial radiological healing } \\
\text { Cinacalcet: } 0.25 \mathrm{mg} / \mathrm{kg} / \text { day }\end{array}$ \\
\hline After 15 days of cinacalcet & 7.9 & 2.7 & 1335 & 503 & $\begin{array}{l}\text { Elemental Ca oral: } 4 \text { g/day } \\
\text { Calcitriol: } 6 \mu \mathrm{g} / \text { day } \\
\text { P: } 1 \text { g/day } \\
\text { Cinecalcet: } 0.4 \mathrm{mg} / \mathrm{kg} / \mathrm{mg} / \text { day }\end{array}$ \\
\hline After 1 month of cinacalcet & 8.9 & 3 & 1100 & 184 & $\begin{array}{l}\text { Elemental Ca oral: } 2 \text { g/day } \\
\text { Calcitriol: } 4 \mu \mathrm{g} / \text { day } \\
\text { Cinacalcet: } 0.4 \mathrm{mg} / \mathrm{kg} / \text { day }\end{array}$ \\
\hline After 4 months of cinacalcet & 9 & 3.1 & 200 & 64 & $\begin{array}{l}\text { Elemental Ca oral: } 2 \text { g/day } \\
\text { Calcitriol: } 2 \mu g / \text { day } \\
\text { Cinacalcet: } 0.25 \mathrm{mg} / \mathrm{kg} / \text { day } \\
\text { Radiological healing observed }\end{array}$ \\
\hline
\end{tabular}


bone features became more apparent in the radiograms. After 4 months of intermittent calcium infusion, serum PTH and ALP levels decreased to near normal levels and radiological improvements were detected, secondary hPTH was normalized temporarily but not improved completely. After these improvements, intravenous calcium treatment was stopped and oral calcium and calcitriol treatment in high doses was administered again. However, after a while, serum PTH and ALP levels started rising again, serum $\mathrm{Ca}$ and $\mathrm{P}$ levels tended to decrease. We started cinacalcet $(0.25$ $\mathrm{mg} / \mathrm{kg}$ ) once a day along with high doses of oral calcium (4 g/day) and calcitriol ( $6 \mu \mathrm{g} /$ day) and the cinacalcet dose was incrementally increased based on serum calcium and PTH levels, reaching $0.4 \mathrm{mg} / \mathrm{kg} / \mathrm{day}$ over the next 2 weeks. We observed a temporary hypocalcemia during cinacalcet therapy. After 4 months of cinacalcet, serum $\mathrm{Ca}$ and P levels were within normal limits and we also observed sustained control of serum PTH and ALP levels and healing of the radiological rickets findings (Figure $1 \mathrm{C}$ ). Treatment has been continued with a decreased dose of calcitriol ( $2 \mu \mathrm{g} /$ day) and oral Ca (2 g/day) along with low-dose cinacalcet.

\section{Case 2}

The proband's sister was a 4-month-old girl with nearly total alopecia since birth (Figure 3). She had no history of hypocalcemic symptoms or seizures. She was taking daily $25(\mathrm{OH}) \mathrm{D}_{3}(400 \mathrm{IU})$. At first visit, we have not observed any pathological features at upper and lower extremities. Her length was $63 \mathrm{~cm}$ (50\% p), weight was $6.5 \mathrm{~kg}$ (25\% p), and she had no radiological findings of rickets. Laboratory examinations showed normal serum $\mathrm{Ca}$ and $\mathrm{P}$ levels; however, serum PTH and ALP levels were high. The same mutation of VDR gene which was previously detected in her sister was also found in this patient. In her next visit after 2 months, serum $\mathrm{Ca}$ and $\mathrm{P}$ levels tended to decrease (Ca: $7.9 \mathrm{mg} / \mathrm{dL}$ and P: $2.8 \mathrm{mg} / \mathrm{dL})$, but PTH (480 pg/mL) and ALP (689 U/L) levels were increased (Table 2). Rickets findings were observed radiologically in her elbow joint (Figure 3a). The same treatment protocol which was applied to her sister was also applied to this patient. At first, she was treated with high-dose calcitriol and intermittent calcium infusion; a temporary metabolic and radiological improvement was detected, as in her sister (Table 2). After adding cinacalcet to the treatment schedule, PTH and ALP levels decreased, serum $\mathrm{Ca}$ and $\mathrm{P}$ levels were sustained within normal levels, and complete radiological healing of rickets was observed (Figure 3b).

Informed consent forms were obtained from the parents of the patients for publication of the cases, including images.

\section{Discussion}

HVDRR results from loss of VDR gene function leading to target-organ resistance to $1,25(\mathrm{OH})_{2} \mathrm{D}_{3}$ which regulates $\mathrm{Ca} / \mathrm{P}$ metabolism and bone mineralization. It is associated with severe rickets, secondary hPTH due to hypocalcemia, and hypophosphatemia with or without alopecia. Serum

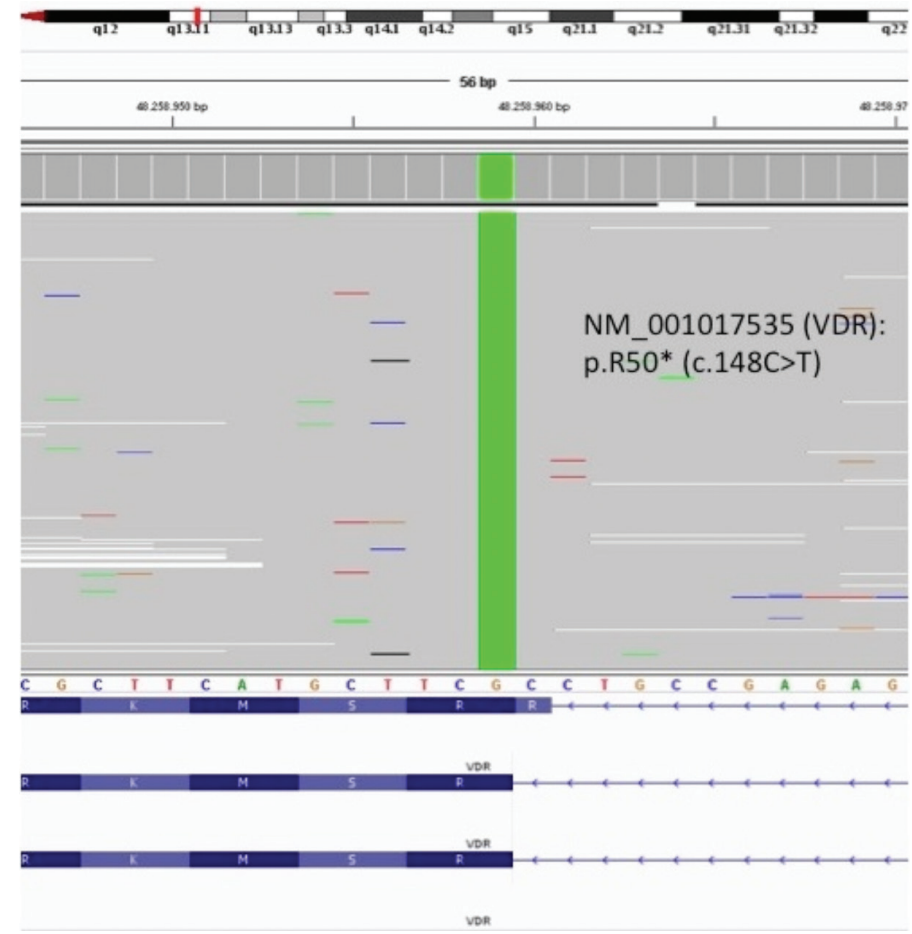

Figure 2. $V D R$ gene analysis performed by using MiSeq next-generation sequencing platform, a Food and Drug Administration-approved diagnostic system (Illumina, San Diego, CA, USA). The gee has 11 exons and NM001017535(VDR): p.R50* (c.148 C > T) is causing a premature stop codon in exon 5. This variation causes a truncated protein and severe damage on protein function
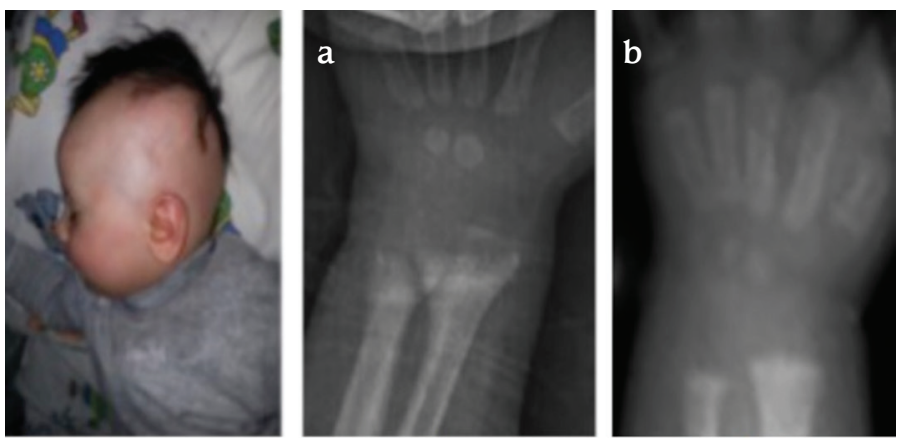

Figure 3. Alopecia and rickets in case 2

3a. Baseline $x$-rays at the age of 4 months showing changes consistent with rickets in case 2

3b. Bone roentgenogram showing markedly improved signs of rickets with high-dose calcitriol, oral calcium, and cinacalcet 
$1,25(\mathrm{OH})_{2} \mathrm{D}_{3}$ level is usually elevated. While $25(\mathrm{OH}) \mathrm{D}_{3}$ levels were within normal limits in our patients, $1,25(\mathrm{OH})_{2} \mathrm{D}_{3}$ levels were in the upper limits of the normal ranges $(1,2,3)$.

Alopecia has been considered as one of the indicators of severe hormone resistance in patients with HVDRR. Though there is genotype-phenotype variability, the severity of alopecia and hormone resistance seems mostly to depend on the different types of VDR mutation in these patients. Several mutations in the VDR gene have been identified as the cause of HVDRR. It has been revealed that most of the patients with mutations in the DNA-binding domain have alopecia, whereas patients with mutations in the ligand-binding domain have variable degrees of vitamin D resistance usually not associated with alopecia $(1,9,10)$. In our patients, we identified a stop-codon mutation in the VDR gene (c.148C > T) in both sisters as previously described in two sisters with alopecia and HVDRR (8). In these patients, the mutation was transmitted in an

Table 2. Effects of treatment with elemental calcium (oral/i.v.), calcitriol, and cinacalcet on serum calcium, phosphorus, alkaline phosphatase, and parathyroid hormone levels in case 2

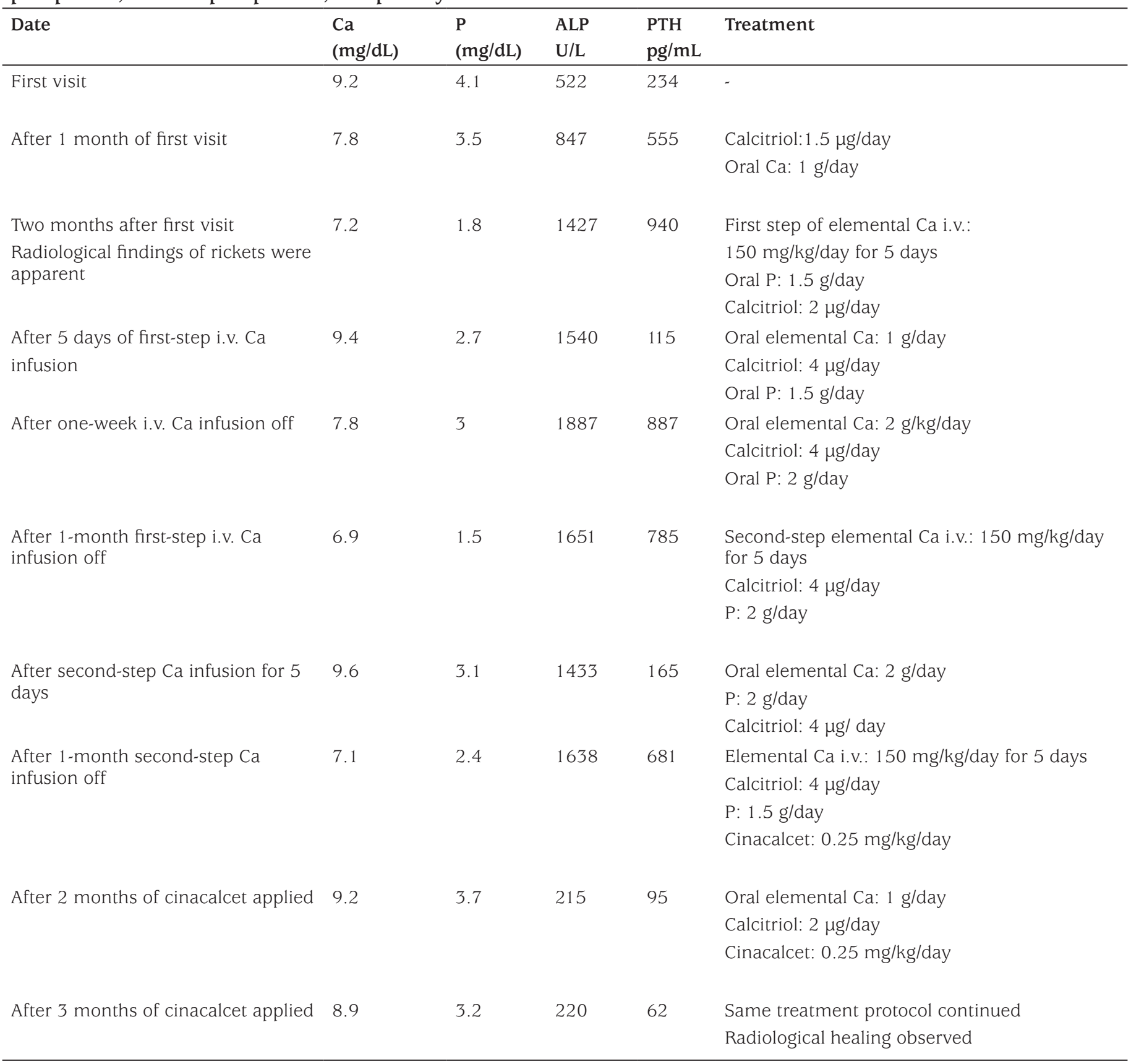

Ca: calcium, P: phosphorus, ALP: alkaline phosphatase, PTH: parathyroid hormone 
autosomal recessive inheritance, and the parents who had the same mutation in heterozygous form were asymptomatic, with no features of metabolic bone disease or alopecia. Our patients had near total alopecia and severe rickets findings on physical examination and X-ray findings similar to those of the two sisters carrying the same VDR mutation, previously reported (8).

In HVDRR, the main metabolic characteristics are severe hypocalcemia-induced secondary hPTH and renal phosphate wasting which prolongs bone healing. Traditional therapy with high-dose oral calcium and calcitriol aims to correct serum $\mathrm{Ca}$ concentration to normal levels and to radiological healing of rickets. However, these treatment protocols are usually not able to suppress the secondarily increased hPTH and ALP levels. Sustained hPTH prolongs the bone healing process by stimulating bone turnover and hypophosphatemia. Actually, serum PTH level is suppressed by ionized serum $\mathrm{Ca}$ concentrations. But it is difficult to maintain normocalcemia and to suppress PTH level in patients with HVDRR, especially patients with alopecia. For these reasons, some authors proposed HVDRR to be a form of PTH-dependent rickets. High doses of calcium and calcitriol treatment which are required to maintain normocalcemia may lead to vitamin D intoxication, nephrocalcinosis, and kidney damage. Moreover, tertiary hPTH and osteitis cystica fibrosa may develop in some patients with $\operatorname{HVDRR}(11,12)$. Some authors recommend parathyroidectomy in patients with HVDRR who have unsuppressed secondary hPTH. It has also been proposed that parathyroidectomy can be considered not only for correction of hypocalcemia but also for PTH suppression to maintain metabolic and radiological improvement in HVDRR. In Case 1, during 2.5 months of high-dose oral calcium and calcitriol therapy, serum Ca concentration reached a near normal level from time to time, but serum P level was lower than normal limits despite phosphorus supplementation, and serum PTH and ALP levels were still extremely elevated. During this period, radiological healing was not observed. Enteral or parenteral calcium infusions are reported to suppress PTH level with metabolic and radiological healing in HVDRR patients with or without alopecia $(4,5,6)$. In our patients, long-term normocalcemia and normalization of hypophosphatemia secondary to unsustained hPTH suppression could not be achieved with high-dose oral calcium and calcitriol treatment. Therefore, we tried treatment with intermittent parenteral calcium infusions. As previously reported, two siblings who had the same mutations in VDR gene were successfully treated with parenteral calcium infusion (8). We observed a decrease in PTH and ALP levels and normalization of serum P levels only during the periods of intravenous calcium infusion. After four-step intermittent calcium infusion (each step covering five days of i.v. calcium infusion in a month), metabolic improvement and partial healing in bone findings was observed; but when the calcium infusions were stopped, secondary hPTH and hypophosphatemia occurred again and rachitic bone features became more apparent in X-rays. Intravenous calcium treatment for a long time is difficult especially in infants because of prolonged hospitalization and increased risk of infection due to central catheter application. For these reasons, alternative therapeutic approaches have been tried to suppress PTH. The recent availability of the calcimimetic agent cinacalcet enables the suppression of PTH secretion through activation of the calcium-sensing receptors. Cinacalcet has been used in adults with primary hPTH or secondary hPTH due to chronic renal disease $(13,14,15)$. The safety and efficacy of cinacalcet in children have been shown in a few reports and in cases of secondary hPTH with disorders such as x-linked hypophosphatemia, HVDRR, and renal failure $(15,16)$. We can only reach the suppressed PTH levels with low-dose cinacalcet combined with high-dose oral calcium and calcitriol therapy. After 4 months of this combination therapy, long-term normocalcemia and PTH suppression with normalization of serum phosphorus level were achieved in addition to radiological healing, but, as expected, there was no recovery in alopecia. Treatment with cinacalcet, as a side effect, may cause hypercalciuria due to activation of calcium-sensing receptors in the thick ascending limb of the loop of Henle, and for this reason, administration of thiazide diuretics may be beneficial (16). Another potential risk of cinacalcet therapy is hypocalcemia due to hypercalciuria. In Case 1, we have observed a temporary hypocalcemia but not hypercalciuria. At the beginning, Case 2 was also treated with high-dose oral calcium and calcitriol, but this proband did not respond to this therapy protocol. We observed only temporary PTH suppression, metabolic and radiological healing with intermittent i.v. calcium infusion (Table 2). Therefore, to achieve long-term metabolic and radiological healing as in Case 1, low-dose cinacalcet was added to the high-dose oral calcium and calcitriol therapy. Both two siblings are at present continuing treatment under the same protocol.

In this report, we described two siblings with HVDDR from parents with consanguinity. Heterozygous mutations in $V D R$ gene were detected in the parents while the children were homozygous for the same mutation. Our patients did not respond to traditional treatment with calcium and calcitriol in high doses, and responded partially to intravenous calcium infusions. In addition to high-dose calcium and calcitriol, by administrating cinacalcet we were able to obtain a positive effect in maintaining the biochemical and radiological 
healing. Thus, we have shown that cinacalcet improves the biochemical and radiological findings in HVDDR and we therefore recommend its use in the management of secondary hPTH.

\section{Ethics}

Informed Consent: Informed consent forms were obtained from the parents of the patients for publication of the cases, including images.

Peer-review: Externally peer-reviewed.

\section{Authorship Contributions}

Concept: Ayşehan Akınc1, Design: Ayşehan Akınc1, Data Collection and Processing: İsmail Dündar, Analysis and Interpretation: Ayşehan Akınc1, Literature Research: Meltem Kıvilcım, Writing: Ayşehan Akınc1.

Financial Disclosure: The authors declared that this study received no financial support.

\section{References}

1. Malloy PJ, Feldman D. Genetic disorders and defects in vitamin D action. Endocrinol Metab North Am 2010;39:333-346.

2. Hochberg Z. Vitamin-D-dependent rickets type 2. Horm Res 2002;58:297-302

3. Demay MB. The hair cycle and vitamin D receptor. Arch Biochem Biophys 2012;523:19-21. Epub 2011 Oct 7

4. Huang K, Malloy P, Feldman D, Pitukcheewanont P. Enteral calcium infusion used successfully as treatment for a patient with hereditary vitamin D resistant rickets (HVDRR) without alopecia: a novel mutation. Gene 2013;512:554-559. Epub 2012 Sep 28

5. Hochberg Z,Tiosano D, Even L. Calcium therapy for calcitriol-resistant rickets. J Pediatr 1992;121:803-808.

6. Ersoy B, Kiremitci S, Isojima T, Kitanaka S. Successful intermittent intravenous calcium treatment via peripheral route in a patient with hereditary vitamin D-resistant rickets and alopecia. Horm Res Paediatr 2015;83:67-72. Epub 2015 Jan 6

7. Srivastava T,Alon US. Cinacalcet as adjunctive therapy for hereditary 1,25-dihydroxyvitamin D-resistant rickets. J Bone Miner Res 2013;28:992-996.

8. Supornsilchai V, Hiranras Y, Wacharasindhu S, Mahayosnond A, Suphapeetiporn K, Shotelersuk V. Two siblings with a novel nonsense mutation, p.R50X, in the vitamin- D receptor gene. Endocrine 2011;40:62-66. Epub 2011 Mar 18

9. Zhou Y, Wang J, Malloy PJ, Dolezel Z, Feldman D. Compound heterozygous mutations in the vitamin-D receptor in a patient with hereditary 1,25-dihydroxyvitamin D-resistant rickets with alopecia. J Bone Miner Res 2009;24:643-651.

10. Malloy PJ, Wang J, Peng L, Nayak S, Sisk JM, Thomson CC, Feldman D. A unique insertion/duplication in the VDR gene that truncates the VDR causing hereditary 1,25-dihydroxyvitamin D-resistant rickets without alopecia. Arc Biochem Biophys 2007;460:285-292. Epub 2006 Oct 16

11. Balsan S, Garabedian M, Larchet M, Gorski AM, Cournot G, Tau C, Bourdeau A, Silve C, Ricour C. Long-term nocturnal calcium infusions can cure rickets and promote normal mineralization in hereditary resistance to 1,25- dihydroxyvitamin D. J Clin Invest 1986;77:16611667.

12. al-Aqeel A, Ozand P, Sobki S, Sewairi W, Marx S. The combined use of intravenous and oral calcium for the treatment of vitamin $D$ dependent rickets type II (VDDRII). Clin Endocrinol (Oxf) 1993;39:229-237.

13. Peacock M,Bilezikian JP, Klassen PS, Gou MD, Tumer SA, Shoback D. Cinacalcet hydrochloride maintains long-term normocalcemia in patients with primary hyperparathyroidism. J Clin Endocrinol Metab 2005;90:135-141. Epub 2004 Nov 2

14. Muscheites J, Wigger M, Drueckler E, Fischer DC, Kundt G, Haffner D. Cinacalcet for secondary hyperparathyroidism in children with endstage renal disease. Pediatr Nephrol 2008;23:1823-1829. Epub 2008 May 27

15. Alon US, Levy-Olomucki R, Moore WV, Stubbs J, Liu S, Quaries LD. Calcimimetics as an adjuvant treatment for familial hypophosphatemic rickets. Clin J Am Soc Nephrol 2008;3:658-664. Epub 2008 Feb 6

16. Nemeth EF, Shoback D. Calcimimetic and calcilytic drugs for treating bone and mineral -related disorders. Best Pract Res Clin Endocrinol Mtab 2013;27:373-384 